\title{
Combined Hepatocardiac Hydatid Cystic Disease
}

\author{
Hazem Aljasem, Ali Khaliphe, Ali Khaddam, Ahmad Al Khaddour* \\ Damascus University Hospital, Damascus, Syria \\ Email: ‘ahmedal@doctors.org.uk
}

Received 20 June 2016; accepted 17 July 2016; published 20 July 2016

Copyright (C) 2016 by authors and Scientific Research Publishing Inc.

This work is licensed under the Creative Commons Attribution International License (CC BY). http://creativecommons.org/licenses/by/4.0/

(c) (i) Open Access

\begin{abstract}
Cardiac echinococcus is a serious problem. Although it is rare, it could cause dangerous complications like anaphylactic shock which could be fatal. In our case a 14-year-old female complained with the intermittent chest pain and had combined cystic lesions in the heart and the liver. The liver cyst was treated conservatively, while the heart cyst was excised by open heart surgery.
\end{abstract}

\section{Keywords}

Echinococcosis, Hydatid Cyst, LAD Left Anterior Descending Artery, CT Scan, Open Heart Surgery

\section{Introduction}

Hydatid disease (cystic echinococcosis), which arises from the Echinococcus granulosus tapeworm, is endemic in some livestock-raising countries [1]. Their life cycle involves only 2 hosts, one definitive and the other intermediate. Human acts as accidental intermediate host. The life cycle has 3 developmental stages: 1) the adult tapeworm in the definitive host; 2) eggs developmental stages; and 3) the metacestode in the intermediate host. Metacestodes are ingested by the definitive host and, in turn, release eggs into the environment. The intermediate host ingests the eggs, which hatches into metacestodes which infest the liver, lungs, and other organs of the intermediate host.

Exposure to food and water contaminated by the feces of an infected definitive host or poor hygiene in area of infestation can lead to echinococcosis.

The most frequent anatomic locations are liver and lung. $75 \%$ of these lesions are single [2]. It is relatively a common disease in Syria [2]. Cardiac involvement is seen in only $0.5 \%$ to $2 \%$ of patients with hydatid disease [1]-[3], and the interventricular septum is involved in just $4 \%$ of cardiac cases [4]. In this study we reported one case of combined hepatocardiac hydatid disease.

${ }^{*}$ Corresponding author. 


\section{Case Presentation}

14-year-old female was complaining of intermittent tight chest pain. Clinical examination revealed an early systolic murmur at the heart apex. An echocardiogram study on this patient revealed a $(4.8 \times 3.8 \mathrm{~cm})$ cystic lesion in the left ventricle eroding the interventricular septum with ejection fraction (EF) of $65 \%$ (Figure 1). The patient was referred to our department for consideration of surgical excision of the cardiac cyst. The patient was still complaining of intermittent tight chest pain. No other symptoms were reported. Her past medical and family history was unremarkable. The physical examination revealed an early systolic murmur at the heart apex, no other specific findings were detected. The results of routine laboratory tests were normal. An enzyme-linked immunosorbent assay (ELISA) was positive for echinococcus antibodies.

A computed tomography (CT scan) study of the chest and abdomen was performed which revealed a $(4.2 \times$ $4.5 \mathrm{~cm}$ ) cystic lesion within the myocardium of the left ventricle eroding the interventricular septum (Figure 2), also It showed a $(3.2 \mathrm{~cm}$ ) cystic lesion in the upper section of the right lobe of the liver (Figure 3), no other lesions were detected.

General surgeon was consulted with regard the hepatic cyst who advised conservative treatment With albendazole as it is considerably a small lesion.

The patient underwent an open heart surgery to excise the cardiac cyst. Under general anaesthesia with one lumen endotracheal intubation median sternotomy was performed, The pericardium was opened. A $(5 \times 5.5 \mathrm{~cm})$ cyst was found within the anterior wall of the left ventricle just next to the left anterior descending artery (LAD) (Figure 4). The surgical field was protected with gauze soaked with hypertonic saline solution. cardiopulmonary bypass instituted using a right atrial single-stage cannula for venous drainage and ascending aortic cannulation for arterial return. The patient was cooled to 35 degrees centigrade, aortic cross-clamp applied and antegrade cold blood cardioplegia infused to achieve prompt cardiac arrest. The most prominent point of the cyst was detected. Clear fluid was aspirated from the cyst. The cyst then was injected with hypertonic solution. The external membrane of the cyst was incised for $2 \mathrm{~cm}$ then the cyst was excised completely and safely (Figure 5). The cavity was approximated with continues 4.0 prolene suture leaving small space for drainage and repair in secondary intention.

The cross-clamp was then released and the heart resumed in sinus rhythm. Cross clamp time was 42 minutes. Cardiopulmonary bypass was discontinued without complications. Two chest drains were inserted, haemostasis secured and the chest closed using 6 single sternal wires. The soft tissues were approximated in two layers. The

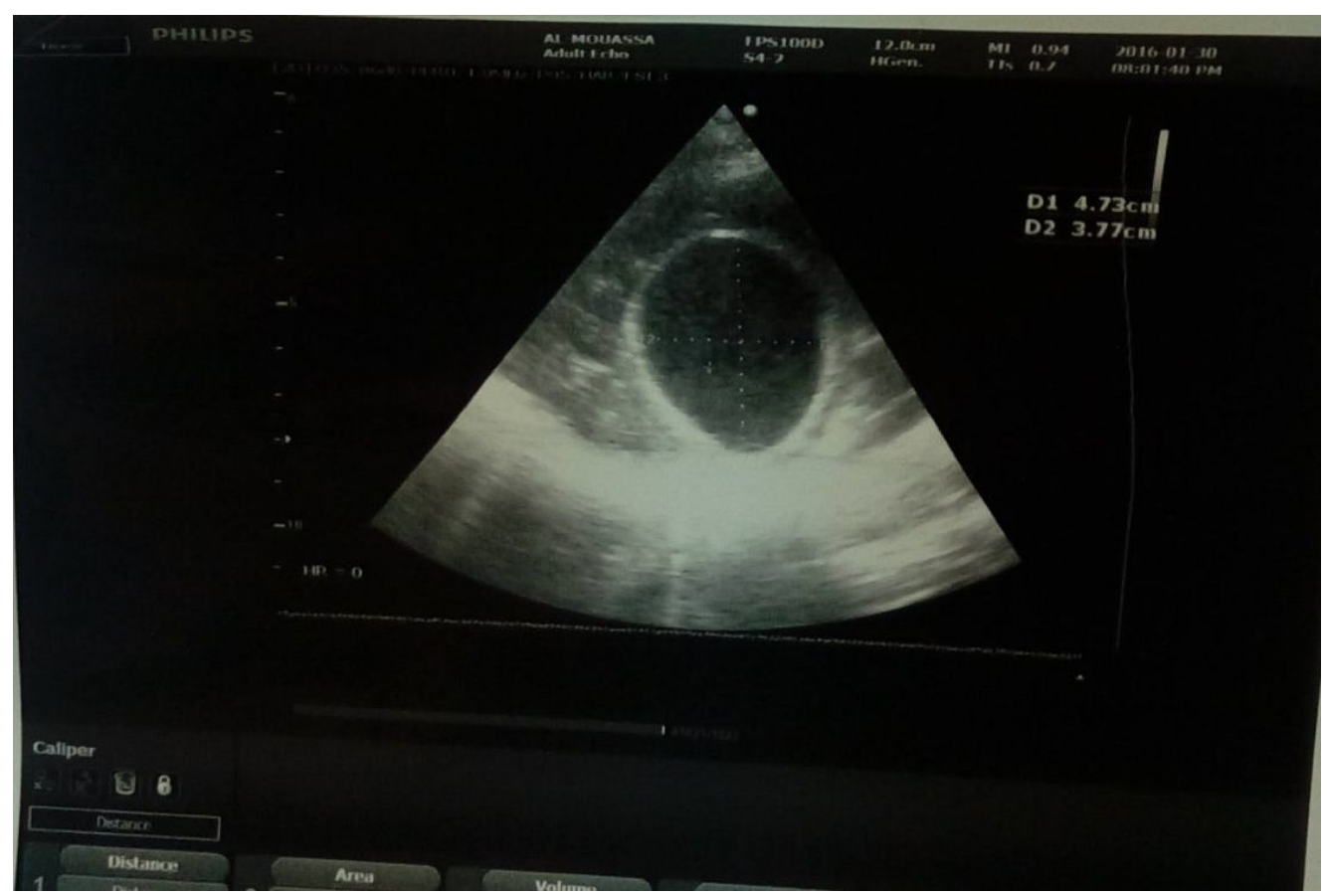

Figure 1. Hydatid cyst in the heart on echography. 


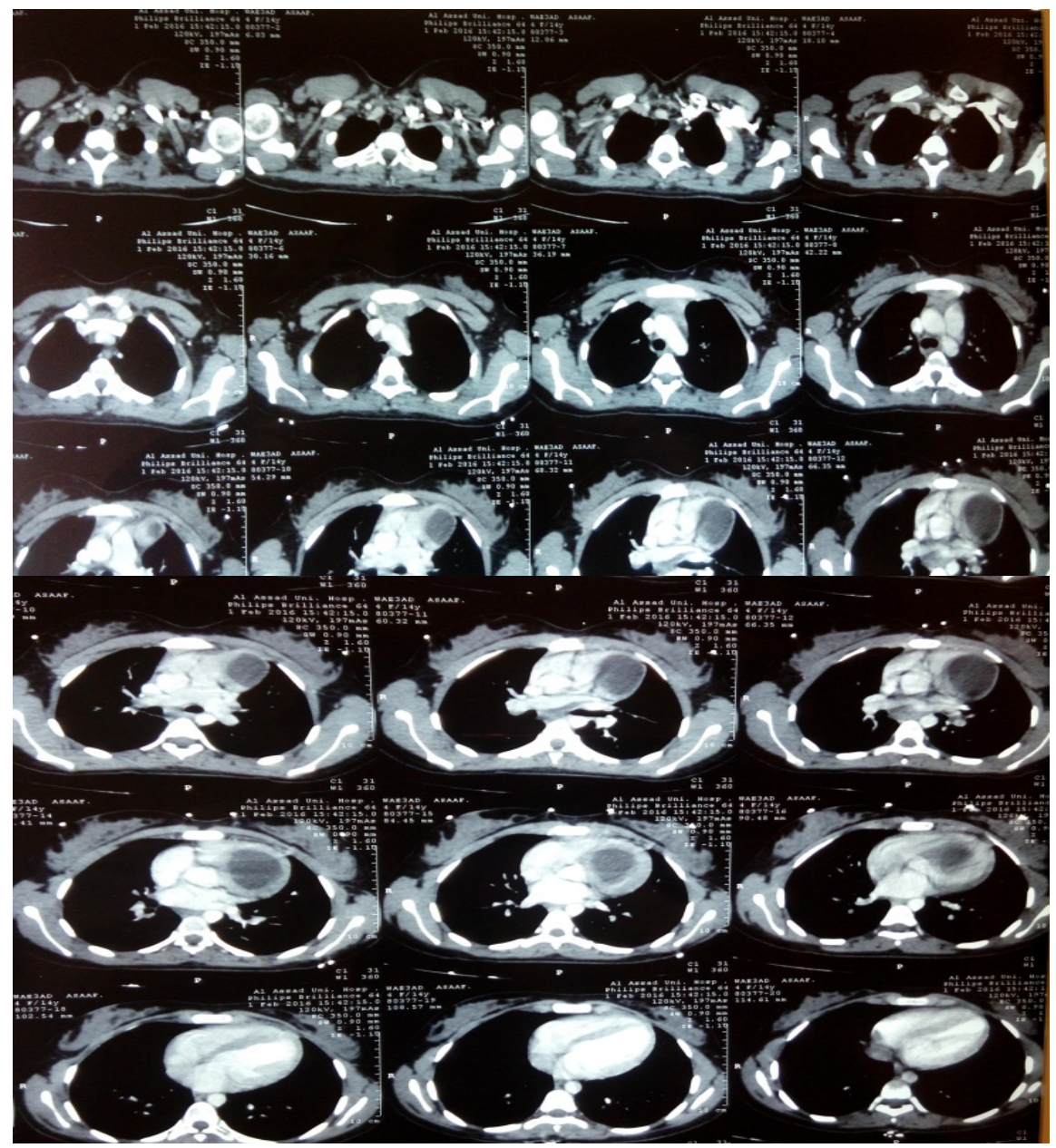

Figure 2. Hydatid cyst in the heart on chest CT with contrast.

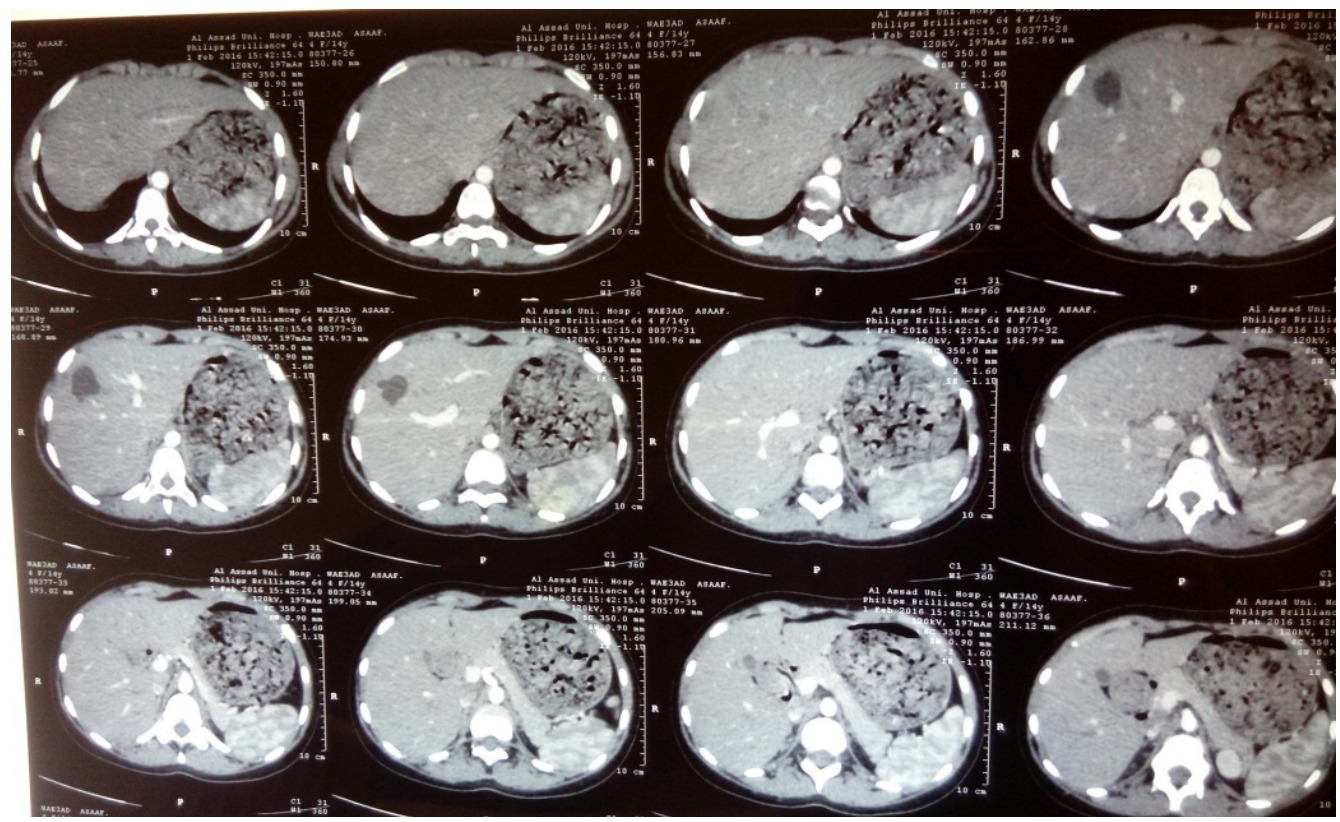

Figure 3. Hydatid cyst in the liver on abdominal CT with contrast. 


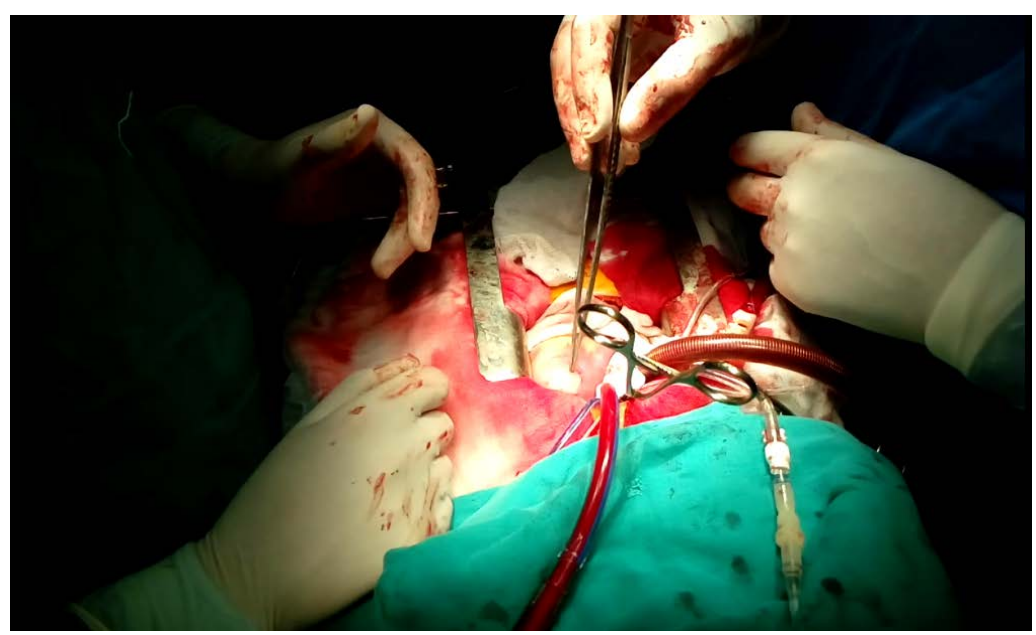

Figure 4. Hydatid cyst in the heart during surgery.

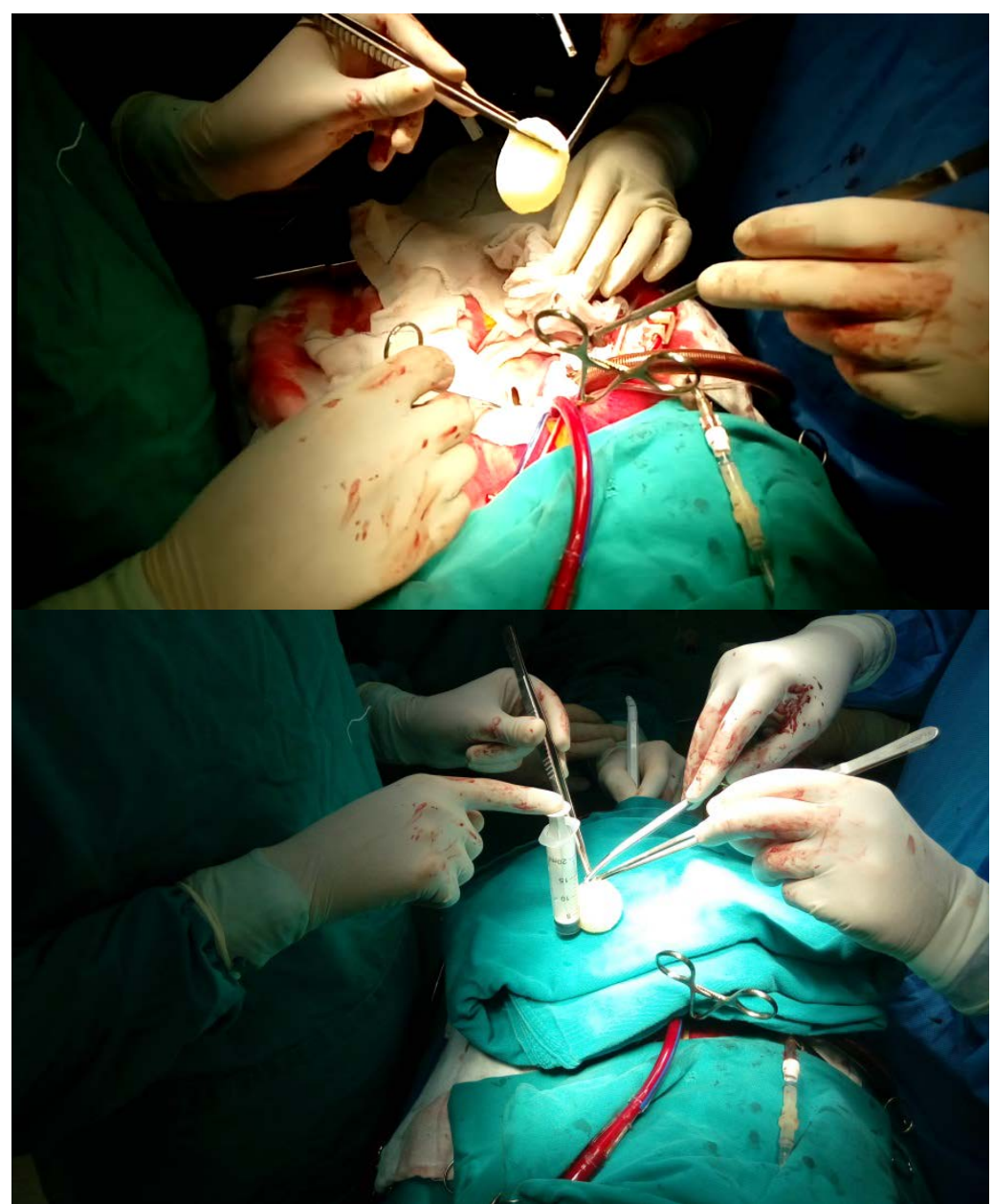

Figure 5. Hydatid cyst after the excision from the heart.

skin was closed using monocryl (absorbable) suture. The patient was extubated five hours postoperatively. Patient had minimal pleural and mediastinal drainage postoperatively. Patient was transferred from the intensive care unit to the ward on the third postoperative day. She was discharged home on the fifth postoperative day without any complication. Her chest CT on discharge was clear. The patient was discharged on oral Albendazol 
for 3 months. Three months later the patient recovered fully with hepatic cyst shrunk in size to 2.2 CM.

\section{Discussion}

This is a rare case of combined hepatocardiac cysts. The management of this case is quite Controversial. The question is Which cyst we are going treat first cardiac or hepatic one. Shall we apply conservative management by chemical therapy or surgical excision.

The clinical picture of a cardiac hydatid cyst depends on the size, location, and integrity of the cyst. Hydatid cyst normally grow slowly (approximately $1 \mathrm{~cm}$ per year). cardiac hydatid cysts is rarely Presented in early childhood. However, cardiac echinococcosis in children has recently been reported in a few studies [5] [6]. The presenting clinical picture may vary from no symptoms to congestive heart failure or even sudden death [6]. It is estimated that $10 \%$ of patients remain asymptomatic for many years, although they are under the continuous threat of rupture [6]. Further, it has been suggested that about $20 \%$ of fatal cases presented with sudden death, having shown no previous signs or symptoms of cardiac echinococcosis [6]. Although the serologic reactions for hydatid cyst (ELISA Test-An Enzyme-Linked Immunosorbant assay) provide essential information, their sensitivity is not high and parameters frequently do not correspond to the morphological changes of the disease [7]. Transthoracic echocardiography and more recently, contrast echocardiography, computed tomography, and magnetic resonance imaging are the most important tools for diagnosis and follow up of the patient [7]. Whereas cysts in other organs may be treated both by chemotherapy and surgical manipulations, in the case of heart echinococcosis it is impossible to administer antihelmintic medicines prior to surgery due to the risk of cyst wall destruction and rupture. In addition the results of surgical treatment of heart echinococcosis are better than the conservative strategy only [8].

\section{Conclusions}

In view of the difficulties of the diagnosis and the progressive and dangerous complications in its natural course, surgical treatment of cardiac echinococcosis is urgent [7]-[9].

The treatment of choice even for asymptomatic cardiac hydatid cysts is surgical excision, which yields complete recovery and excellent prognosis [6]. Although superficially located cysts can successfully be removed with a beating-heart (off-pump) technique, resection under cardiopulmonary bypass, since 1962, has been considered the safest method, with the least risk of spillage of cyst contents during the procedure [6]. In our study the patient had combined heart and liver cysts, the latter is decided to be managed conservatively and the former was excised surgically under cardiopulmonary bypass. This study was approved by our ethical committee and it was presented at our hospital weekly scientific meeting. The patient gave the appropriate consent and agreed with the study.

\section{References}

[1] Pakis, I., Akyildiz, E.U., Karayel, F., Turan, A.A., Senel, B., Ozbay, M. and Cetin, G. (2006) Sudden Death Due to an Unrecognized Cardiac Hydatid Cyst: Three Medicolegal Autopsy Cases. Journal of Forensic Sciences, 51, 400-402. http://dx.doi.org/10.1111/j.1556-4029.2006.00056.x

[2] Al Khaddour, A., Al Hashimi, S. and Abbas, N. (2016) Combined Procedure for Coronary Artery Bypass Grafting and Pulmonary Hydatid Disease. World Journal of Cardiovascular Surgery, 6, 14-18. http://dx.doi.org/10.4236/wjcs.2016.61003

[3] Aleksic-Shihabi, A. and Vidolin, E.P. (2008) Cystic Echinococcosis of the Heart and Brain: A Case Report. Acta Medica Okayama, 62, 341-344.

[4] Dursun, M., Terzibasioglu, E., Yilmaz, R., Cekrezi, B., Olgar, S., Nisli, K. and Tunaci, A. (2008) Cardiac Hydatid Disease: CT and MRI Findings. American Journal of Roentgenology, 190, 226-232. http://dx.doi.org/10.2214/AJR.07.2035

[5] Cakir, O., Eren, N. and Kilinc, N. (2002) Cardiac Hydatic Cyst Causing Cerebral Emboli in a Child. Pediatric Cardiology, 23, 555-556. http://dx.doi.org/10.1007/PL00021006

[6] Yaliniz, H., Tokcan, A., Salih, O.K. and Ulus, T. (2006) Surgical Treatment of Cardiac Hydatid Disease: A Report of 7 Cases. Texas Heart Institute Journal, 33, 333-339.

[7] Tsigkas, et al. (2010) Heart Echinococcus Cyst as an Incidental Finding: Early Detection Might Be Life-Saving. Journal of Cardiothoracic Surgery, 5, 124. http://dx.doi.org/10.1186/1749-8090-5-124 
[8] Shevchenko, Y., Travin, N., Musaev, G. and Morozov, A. (2005) Heart Echinococcosis: Current Problems and Surgical Treatment. Multimedia Manual of Cardiothoracic Surgery, 139. Article ID: 001115.

[9] Rai, N. and Sarkar, U. (2009) Hydatid Cyst of the Heart: An Uncommon Lesion. IJTCVS, 25, 211-213. http://dx.doi.org/10.1007/s12055-009-0047-3

\section{Submit or recommend next manuscript to SCIRP and we will provide best service for you:}

Accepting pre-submission inquiries through Email, Facebook, LinkedIn, Twitter, etc.

A wide selection of journals (inclusive of 9 subjects, more than 200 journals)

Providing 24-hour high-quality service

User-friendly online submission system

Fair and swift peer-review system

Efficient typesetting and proofreading procedure

Display of the result of downloads and visits, as well as the number of cited articles

Maximum dissemination of your research work

Submit your manuscript at: http://papersubmission.scirp.org/ 